\title{
Insecticidal effects of aqueous extracts of wild pomegranate peel and seed (Punica granatum L.) against rose aphids, Macrosiphum rosaeformis
}

\author{
Garima Gupta ${ }^{1^{*}}$, Kriti Dharma and Neelima R. Kumar* \\ *Department of Zoology, Panjab University, Chandigarh 160014 (Chandigarh), INDIA \\ Corresponding author. E-mail: gari_g79@yahoo.com \\ Received: September 22, 2016; Revised received: February 24, 2017; Accepted: July 11, 2017
}

\begin{abstract}
Efficacy of wild pomegranate (Punica granatum Linn.) fruit peel and seeds aqueous extract was evaluated for the control of common insect pests aphids (Macrosiphum rosaeformis) and for its influence on useful non-target predators viz., Coccinella septempunctata. Lethal doses of daru peel and seed suggested these became more toxic to aphids after $24 \mathrm{hr}$ of exposure. A significant difference was obtained in percentage aphids reached to untreated leaves over peel extract treated leaves (23:57 and 23:77) and seed extract treated leaves (7:80 and 17:80) at 90 and 180 min time intervals in food choice assays. No significant effect was observed against Coccinella. LC 50 values of daru peel and seed extracts along with mixture of three flavonoids (Kaempferol, Quercetin and Myricetin) were assessed at $48 \mathrm{hr}$ values were $34.9,4.7$ and $0.6 \mathrm{mg} / \mathrm{ml}$ and at $72 \mathrm{hr}$ these were 16.1, 0.000001 and 0.00001 $\mathrm{mg} / \mathrm{ml}$, respectively. In both the cases field bioassays showed affectivity till 7 DAT. Field data indicated that only X1 $(1 \mathrm{mg} / \mathrm{ml})$ and $\mathrm{X} 2(0.1 \mathrm{mg} / \mathrm{ml})$ concentrations of mixture were effective till 11 days after treatment. These are the first reports of the toxic effect of wild pomegranate (daru) fruit peel aqueous extract against $M$. rosaeformis, hence the study suggests possible usage of Punica granatum peel for the control of rose aphids.
\end{abstract}

Key words: Botanical insecticides, Eco-friendly agriculture, Plant extracts, Punica granatum

\section{INTRODUCTION}

Daru (Punica granatum) also known as 'wild pomegranate' grows wild in very large numbers in the forests and wastelands of the sub-Himalayan region (Parmar and Kaushal, 1982). It grows in the hill slopes of Jammu and Kashmir and Himachal Pradesh (Mir et $a l ., 2012)$. Daru is a deciduous shrub or tree up to 10 meters high, stem woody and bear thorns. The fruits of Daru are much smaller in comparison to the cultivated pomegranate, is yellowish green in colour with a tinge of red. Seeds are fleshy, pinkish white in colour. Fruits of daru are not consumed fresh due to presence of excessive acid content. The seeds are sun dried for making 'anardana' a relished condiment (Parmar, 1913).

Fruit peel and seeds of Punica sp. is characterized by containing substantial levels of flavonoids (Dipak et al. 2012, Zhao et al. 2014, Jung, 2015). Flavonoids are secondary metabolites not only waste products which are produced during cell metabolism, but they apparently act as defence and signalling compounds as well as protecting the plant from various distress conditions. Flavonoids play an adaptive role in plant defence to various adverse conditions as reported against bacterial and fungal diseases (Dahham et al., 2010, Devi et al., 2011). Also they may act as potential insecticide (Xiaofeng et al., 1999, Kotkar et al., 2002, Upasani et al., 2003, Ateyyat et al., 2012, Ghaly et al., 2014). Flavonoids are also known to modulate the feeding and oviposition behaviour of insects (Golawaska and Lukasik, 2012).

The present study was aimed to explore the feasibility of the use of daru fruit peel and seed aqueous extract on economically serious pests (aphids) of ornamental crop (roses) where pest management depends on chemical applications.

\section{MATERIALS AND METHODS}

Plants used: Tea hybrid red roses, Rosa $s p$. were used in the present study. These plants were obtained from Bagia Nursery, Sector 25, Chandigarh, on 11.08.2015 and were grown in green house maintained by the Department of Zoology, Panjab University, Chandigarh, India. These were used as host plant for culturing aphids Macrosiphum roseiformis, as well as to perform field bioassays.

Insects/ mites used: Natural populations of rose aphids (Macrosiphum roseiformis D) were collected from two different locations in and around Chandigarh (Rose garden, Panjab University, Chandigarh and Village-Chapper Chiri, Mohali, Punjab). Aphids were cultured in green house on rose plants for few generations. These were used for the experimentation later.

Plant extracts preparation: Wild pomegranate fruits (Daru) (Punica granatum) were collected from a location in Solan (Latitude 30.9167 and Longitude 77.1167), Himachal Pradesh, India. The samples of these plant materials were sent to the Department of 
forest products, YSP University of Horticulture and Forestry, Solan, Himachal Pradesh, India, for identification and a catalogue number-1352 was obtained.

For preparation of aqueous extracts fruits of wild pomegranate (Daru) were washed thoroughly first with simple tap water and then with rectified alcohol. The peels and seeds of the fruits were removed and kept for drying on soaking sheets for a day or two at room temperature $\left(25\right.$ to $\left.30^{\circ} \mathrm{C}\right)$. These fruit materials were then dried in an oven (dehydrator) at $50{ }^{\circ} \mathrm{C}$ till the peels and seeds were completely dried for grinding. Dried peels and seeds were powdered using a mixer grinder. For the preparation of aqueous extract $250 \mathrm{ml}$ of distilled water was poured in $50 \mathrm{~g}$ of each powder and was allowed to soak for $24 \mathrm{hr}$. Then this mixture was grinded in a mixer grinder for $5 \mathrm{~min}$. It was then squeezed and sieved through muslin cloth. The extracts of the plant material were filtered through filter paper (Whatmann filter paper $125 \mathrm{~mm}$ ) and this concentration was considered as first concentration (X or X1 $=200 \mathrm{mg} / \mathrm{ml}$ ) of extract to be tested in pests/ predator bioassays. Further five serial dilutions were made (making half the concentration taken each time serially) to obtain $0.5 \mathrm{X}$, $0.25 \mathrm{X}, 0.125 \mathrm{X}, 0.0625 \mathrm{X}$ and $0.03125 \mathrm{X}$ respectively denoted as X1, X2, X3, X4, X5, X6 respectively. Only water was taken as control treatment. Each concentration was kept in refrigerator for further use for a week and later it was discarded. Fresh extracts were made for further experimentation.

Components tested (Flavonoids): Some flavonoids Kaempferol, Quercetin and Myricetin were purchased from Sigma- Aldrich India with catalogue numbers 60010, Q4951 and M6760 respectively. For each component, the highest concentration tested was $1 \mathrm{mg} /$ $\mathrm{ml}$ (X1) further five serial dilutions were made (making one tenth the concentration taken each time serially) the concentrations made were labelled as $\mathrm{X} 2$, X3, X4, X5, X6 respectively.

\section{Experimental design and methodology:}

Toxicity bioassays: To evaluate the toxic effect of these natural plant extracts on the experimental pests and predator, bioassays were conducted. Slightly modified methodology from Kumar and Chapman (1984) was adapted for these bioassays. Compound rose leaflets were collected and washed thoroughly with water. These were treated with the prepared six concentrations of all the extracts and components (X1, X2, X3, X4, X5 and X6). After air drying, these treated leaflets were kept in petridish $(90 \times 15 \mathrm{~mm})$. Leaflets, untreated but washed with water, were taken as control. Ten aphids were released in each petridish. Three replicates for each concentration were made and the whole experiment was repeated two times at different dates. To determine the toxic effect of the extracts and components, the mortality data on the test insects were recorded 24, 48 and 72 hours after treatment. Insects were judged to be dead if they did not respond to prodding with a camel hair brush or slight heating under the table lamp. Median lethal dose $\left(\mathrm{LC}_{50}\right)$ values were calculated by the computer programme POLO-PC (Copyright LeOra Software 1987).

Residue bioassays: Sixty-six rose plants were grown outside the zoology department in earthen pots (3 gallon) for field bioassay. Four highest concentrations of all the extracts and components were taken and sprayed on rose plants individually and three plants taken as control were sprayed only with water. On first day of the experiment four leaf samples from each plant were collected and placed in petridishes, 10 insects were released and number of survived insects was observed after 24 and $48 \mathrm{hrs}$. Similar steps were repeated on 3rd day, 5th day, 7th day, 9th day, 11th and 13th day of the experiment (DAT= Days after treatment). Data were analyzed by all replicates combined with ANOVA and means were compared using Student's t test (JMP SAS 2005).

Food choice test (for thrips, aphids and spider mites): Aqueous extracts of peel and seeds were prepared as described earlier and only the first concentration (X) was taken for these assays. Behavioural response (food choice) of aphids was studied by giving them two choices to see whether there was any preference or non-preference to a particular plant extract. Rose leaves were cut to square shape discs (size $2.5 \mathrm{x}$ $2.5 \mathrm{~cm})$ and four leaves were kept in a petridish $(140 \mathrm{x}$ $20 \mathrm{~mm}$ ) lined with a moistened filter paper (Whatman filter paper $125 \mathrm{~mm}$ ). Extract treated and untreated leaf discs were arranged alternately around the circumference of the petridish. These were placed in the petridish at diagonal position. Ten adult aphids were released at the centre of the petridish. Observations on number of aphids, present on treated or untreated rose leaf discs were taken at 30,90 and $180 \mathrm{~min}$ after the release. Three replicates for each treatment were made. Replicates were combined and data were analyzed. $\mathrm{c}^{2}$ goodness of fit analysis was performed using PROC FREQ to determine if the choice responses deviated significantly from random choice $(1: 1,50 \%)$ (JMP, SAS 2005).

\section{RESULTS}

Laboratory bioassays: Figs. 1A and 1B, represents percentage mortality of aphids with treatment of Punica granatum daru peel and seed aqueous extracts respectively, at 24, 48 and $72 \mathrm{hr}$ after treatment. At $24 \mathrm{hr}$ the percentage mortality of aphids with kaempferol (Fig. 1C) was significantly higher than control at concentrations $\mathrm{X} 1$ and $\mathrm{X} 2$ and with quercetin (Fig. 1D) it was significantly higher than control at all concentrations tested. However, myricetin (Fig. 1E) showed non -significantly difference between control and different concentrations. Similar to daru peel and seed extracts, kaempferol and quercetin also showed significantly higher percentage mortality at all the concentrations 
Garima Gupta et al. / J. Appl. \& Nat. Sci. 9 (3): 1397 - 1405 (2017)

Table 1. Lethal concentrations $\left(\mathrm{LC}_{50} \mathrm{mg} / \mathrm{ml}\right)$ of daru fruit peel and seed aqueous extracts and mixture of flavonoids against aphids.

\begin{tabular}{llllllllll}
\hline \multirow{2}{*}{ Treatments } & $\mathbf{2 4 h \mathbf { h r }}$ & \multicolumn{3}{c}{$\mathbf{4 8 h \mathbf { h }}$} & \multicolumn{3}{c}{$\mathbf{\text { 72hr }}$} \\
\cline { 2 - 11 } & $\mathbf{L C}_{\mathbf{5 0}}$ & Slope & $\chi^{2}$ & $\mathbf{L C}_{\mathbf{5 0}}$ & Slope & $\chi^{2}$ & LC $_{\mathbf{5 0}}$ & Slope & $\chi^{2}$ \\
\hline Daru peel & 75449.13 & 0.1 & 0.7 & 34.98 & 0.3 & 0.7 & 16.1 & 0.4 & 2.1 \\
Daru seed & 8695.94 & 0.3 & 0.8 & 4.76 & 0.5 & 2.9 & 0.000001 & 0.1 & 1.3 \\
Mix of Flavo- & 0.28 & 0.4 & 1.4 & 0.61 & 0.4 & 0.7 & 0.00001 & 0.2 & 0.4 \\
noids & & & & & & & & &
\end{tabular}
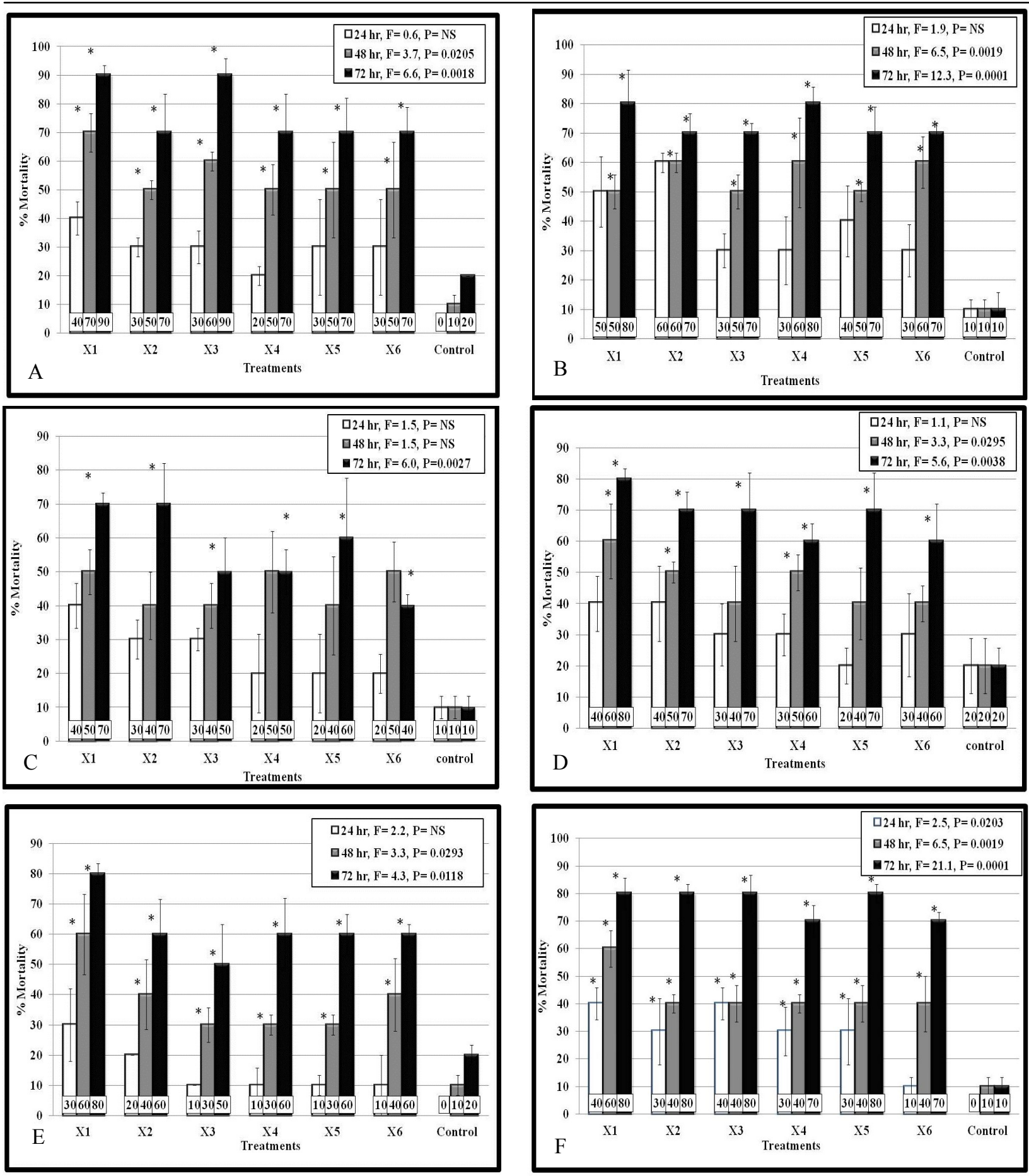

Fig. 1. Average percentage mortality $( \pm S E M)$ of aphids released on rose leaves treated with different concentrations of $(A)$ daru peel, (B) daru seed extract, (C) kaempferol, (D) quercetin, $(E)$ myricetin and $(F)$ mixture of all flavonoids by leaf dip method. Means in the same column followed by a common letter are not significantly different ( $\alpha=0.05$, Student's $t$ LSD Test). 


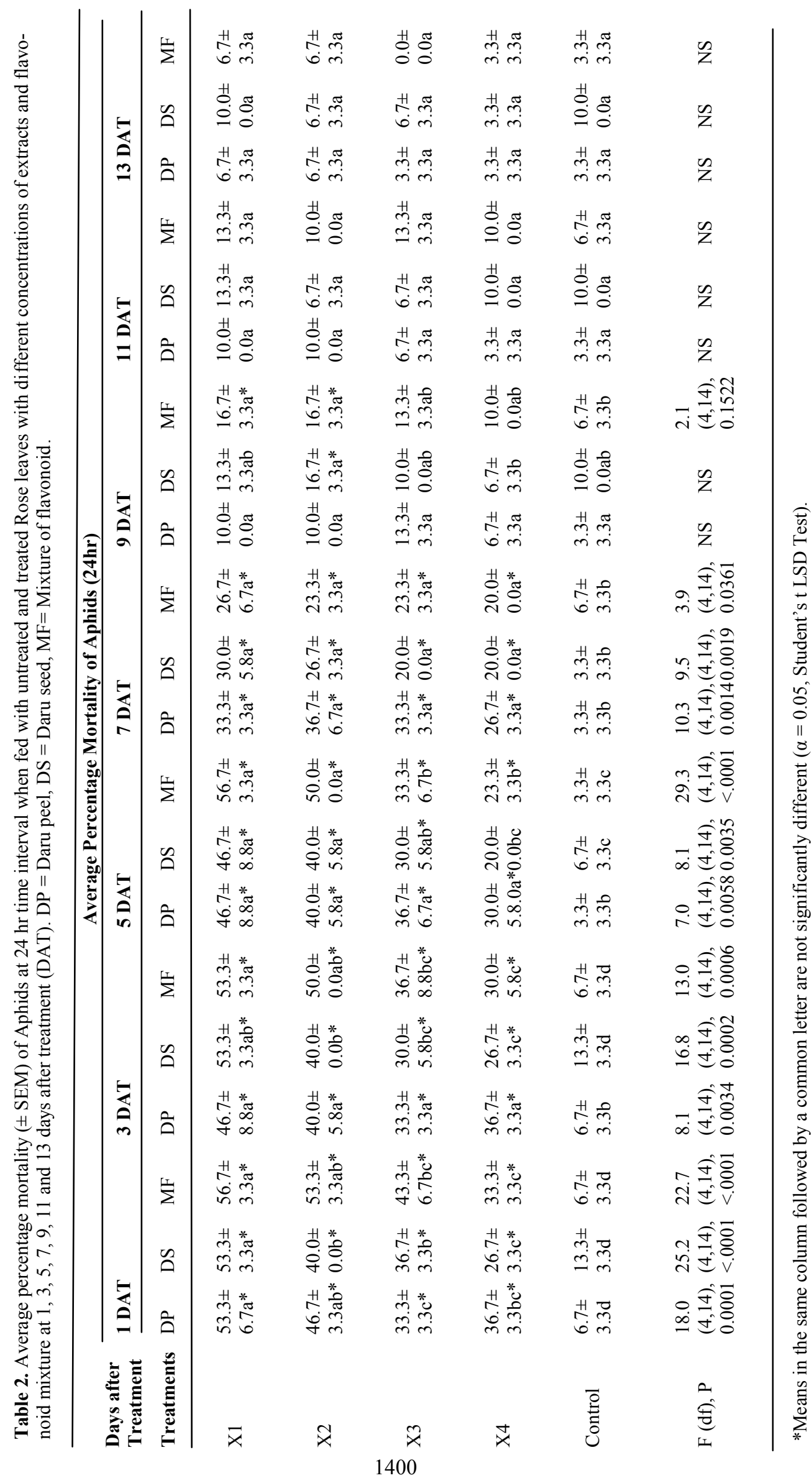


Garima Gupta et al. / J. Appl. \& Nat. Sci. 9 (3): 1397 - 1405 (2017)

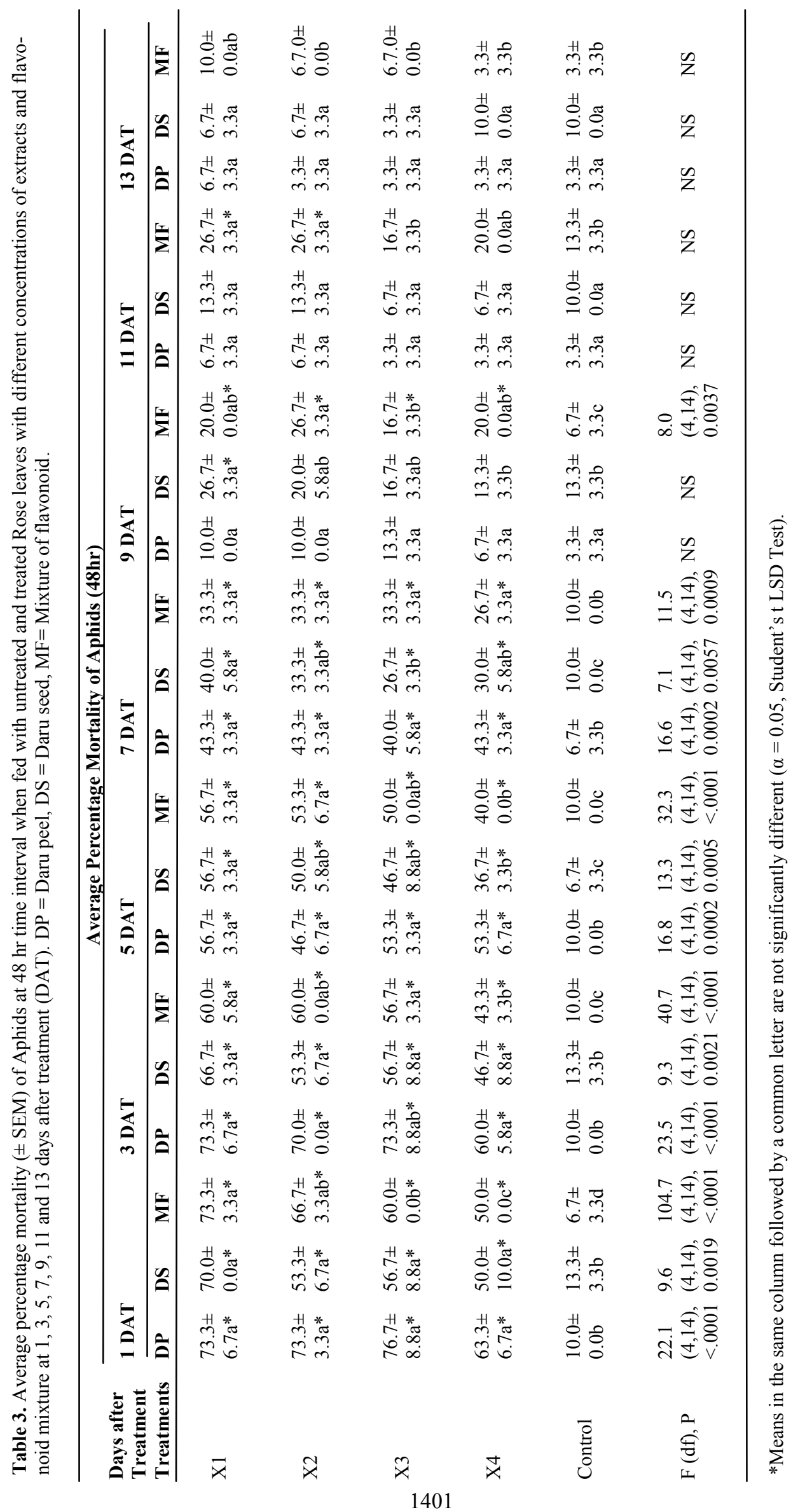



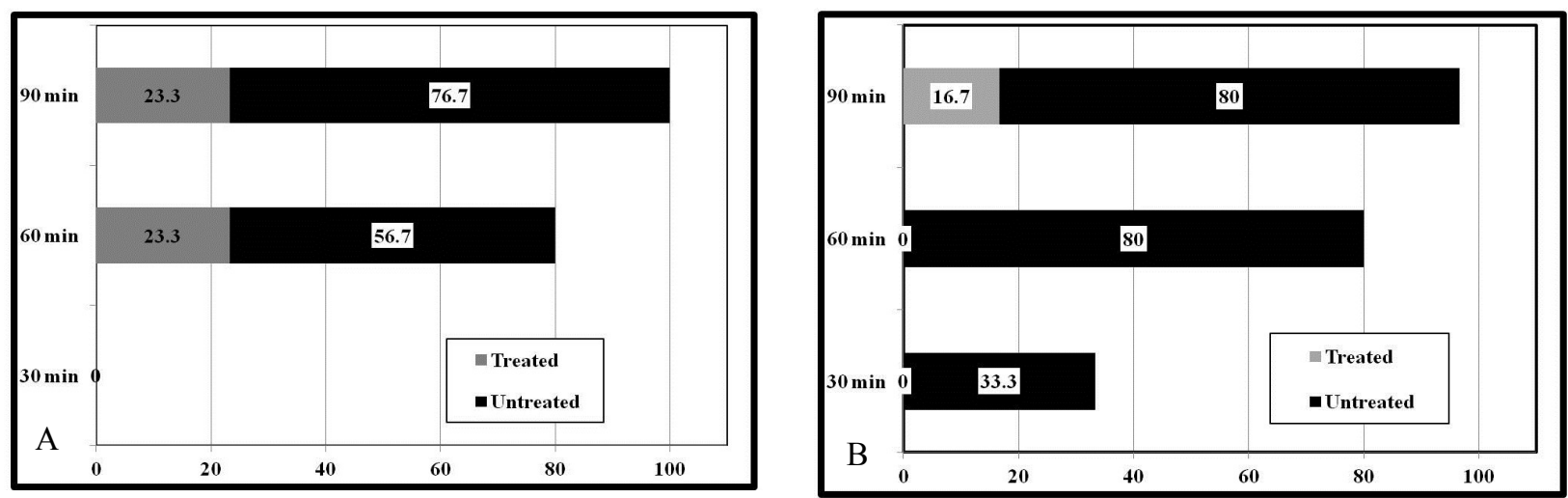

Fig. 2. Food choice assays for aphids. Percentage aphids made choice for untreated or treated rose leaves at 30, 90 and 180 min after release (A) Daru Peel (B) Daru Seed.

tested at 48 and $72 \mathrm{hr}$ when compared to control and with myricetin at $48 \mathrm{hr}$ two highest concentrations X1 and X2 showed significantly higher percentage mortality (Fig. 1E). However, at $72 \mathrm{hr}$ all the concentrations exhibit significantly higher mortality than control. Mixture of flavonoids at 24, 48 and $72 \mathrm{hr}$ showed that percentage mortality of aphids was significantly higher than control at almost all the concentrations tested (Fig. 1F). All the $\mathrm{P}$ values less than 0.05 are considered significant. The However $\mathrm{LC}_{50}$ values obtained with daru peel, seed extracts, and mixture of flavonoids at 24, 48 and $72 \mathrm{hr}$ are shown in Table 1.

Field bioassay: Field bioassays with daru peel and seeds indicated that the percentage mortality of aphids at different days after treatment (DAT) for all four concentrations tested were significantly higher than control till 7 DAT at both 24 (Table 2) and $48 \mathrm{hr}$ (Table 3) of exposure on treated leaves. On 9 DAT, 11 DAT and 13 DAT the values were non-significantly different than control. Mixture of flavonoids showed significantly higher mortality of aphids than control up to 9 DAT at two highest concentrations X1 and X2 after $24 \mathrm{hr}$ and at all four concentrations after $48 \mathrm{hr}$. Percentage mortality at 13 DAT were non-significantly different than control.

Food choice assays: Average percentage of aphids on rose leaves treated with daru peel extract (highest concentration X) compared to untreated rose leaves at 30 , 90 and 180 minute observation time, was $0: 0 \%, 23.3$ : $56.7 \%\left(\chi^{2}=5.5 ; \mathrm{p}=0.0185^{*}\right)$ and $23.3: 76.7 \%\left(\chi^{2}=\right.$ $\left.8.32 ; \mathrm{p}=0.0039^{*}\right)$ respectively (Fig. 2A) and with daru seed it was $0: 33.3 \%, 6.7: 80 \%\left(\chi^{2}=8.32 ; \mathrm{p}=\right.$ $\left.0.0039^{*}\right)$ and $16.7: 80 \%\left(\chi^{2}=8.32 ; \mathrm{p}=0.0039 *\right)$ respectively (Fig. 2B). In both the cases (seeds and peel) at 30 minute observations chi-square test cannot be done as the values were less than 5 .

\section{DISCUSSION}

Toxicity assays conducted in laboratory with daru peel and seed extracts showed significantly high values of percentage mortality of aphids at all the concentrations tested from X1 $(200 \mathrm{mg} / \mathrm{ml})$ to $\mathrm{X} 6(6 \mathrm{mg} / \mathrm{ml})$ at 48 and $72 \mathrm{hr}$ after treatment (Fig. 1A-B). In addition, at $24 \mathrm{hr}$ in both the cases higher three concentrations (X1, X2 and X3) caused significantly more mortality of aphids than control. $\mathrm{LC}_{50}$ values of daru peel and seed extracts at $24 \mathrm{hr}$ showed (Table 1) much higher values than the highest concentration tested (Fig. 1A-B). However, at $48 \mathrm{hr}$ these values were even lower than lowest concentration. This data suggested that daru peel and seed became more effective against aphids after $24 \mathrm{hr}$ of exposure. In both the cases field bioassays showed affectivity till 7 DAT (Table 1 and 2). In addition, food choice assays revealed high repellent effect of rose leaves treated with daru extracts (peel or seed) on aphids, where in almost $80 \%$ preferred control leaves as compared to $20 \%$ found on treated leaves (Fig. 2). With mixture of flavonoid, $\mathrm{LC}_{50}$ values obtained at 24 , 48 and $72 \mathrm{hr}$ after release were $0.28,0.612$ and $0.00001 \mathrm{mg} / \mathrm{ml}$ respectively. Field data indicated that only X1 $(1 \mathrm{mg} / \mathrm{ml})$ and X2 $(0.1 \mathrm{mg} / \mathrm{ml})$ concentrations of mixture were effective till 11 days after treatment. However, lower concentrations did not show any affectivity after 9 DAT (Table 1 and 2).

In the present study it was observed that daru peel and seed aqueous extracts exhibited significant toxic and repellent effects towards aphids which were in agreement with other studies. In earlier studies, Hamouda et al. (2015a) tested aqueous, ethanolic, and methanolic fruit peel extracts of $P$. granatum for their insecticidal activities against Myzus persicae and Phthorimaea operculella. Significant mortalities of $29 \%, 53 \%, 55 \%$ respectively were recorded on adults of $M$. persicae treated with peel extracts, similar effects were noticed on the first larval penetration of $P$. operculella into potato tubers. Application of all extracts on infested tubers reduced egg laying of $P$. operculella in comparison to untreated tubers. Number of eggs 4.8, 6.6 and 8.4 /tuber respectively on an average was laid on treated tubers. Hamouda et al. (2015b) evaluated the feeding activity, nutritional indices and morphological abnormalities of Spodoptera littoralis in response to 
methanol, ethanol and aqueous extracts of $P$. granatum peel. Peel extracts showed promising effects for the control of African Cotton Leaf worm by disrupting development and causing deformities involved in vital activities like feeding, walking or flying, making the insect vulnerable to several sorts of mortality agents and preventing them from causing damage to the crop. Zhao et al. (2014) selected four cultivars of Chinese pomegranate i.e. hongbaoshi, lvbaoshi, shuijingtian and moshiliu for their flavonols and flavones assay. Three flavonols quercetin, myricetin, kaempferol and two flavones apigenin and luteolin were detected in all of the pomegranate samples. Kaempferol was the most abundant in fruit peel of hongbaoshi, lvbaoshi and shuijingtian cultivars being37.15 137.15 mg 100g-1 fw (fresh weight), 31.98 88.29 mg 100g-1, and $25.98 \sim 70.12 \mathrm{mg} 100 \mathrm{~g}-1 \mathrm{fw}$, followed by quercetin which was 52.24, 33.25 and $47.46 \mathrm{mg} 100 \mathrm{~g}-1 \mathrm{fw}$. Myricetin was most prominent in moshiliu with concentration of 59.78 to $185.27 \mathrm{mg} 100 \mathrm{~g}-1 \mathrm{fw}$. Among the flavones the level of luteolin was higher than that of apigenin in all the four cultivars. Jung (2015) analysed each part of pomegranate -root peel, stem peel and fruit peel extracted with ethanol and confirmed the presence of pseudopelletierine and terpene compounds by the GC/MS analysis. Dipak et al. (2012) reported that active ingredients found in different parts of pomegranate, such as ellagitannin (punicalagins), punicic acid, flavonoids, anthocyanins, estrogenic, flavonols, flavones, were responsible for its application in many fields. Pomegranate from different localities showed diverse phytochemical contents. Rahimi et al. (2012) analysed phytochemicals present in pomegranate peel and reported the presence of ellagitannin and gallotanin (Granatin B, Punicalagin), catechin and procyanidins (catechin-(4, 8)-gallocatechin), gallocatechin, anthocyanins and anthocyanidins, cyanidin, which possessed antioxidant, pharmacological, toxicological and anti-inflammatory activities. According to Chebaibi and Filali (2013), peel aqueous extracts of pomegranate contained glycosides, tannin and phenolic compounds.

Aphicidal effect with other plant extracts has also been noticed, such as bulbs of Allium sativum, leaves of Annona squmosa, Annona reticulate and neem (Azadirachta indica) were tested against rose aphids (Macrosiphum rosaeformes Davis) and it was observed that $A$. sativum was more effective than others (Dhembare et al., 2011). Iqbal et al., (2011) suggested that wheat aphid could be controlled by extracts of peel of orange (Citrus sinensis) and bitter gourd (Momordica dioica), fruits of garlic (Allium vineale) and hot pepper (Capsicum frutescens). Citrus sinensis showed highest mortality of $65 \%$ followed by garlic 58\%. Sohail et al. (2012) demonstrated the toxicity effects of several plant extracts such as Azadirachta indica, Allium sativum, Achillea santolina, Salvia of- ficinalis, Thymus vulgaris and Senecio vernalis against aphid Toxoptera aurantii .

In this study, statistically analyzed observations on percentage survival of lady bird beetles exposed to rose leaves treated with both the pomegranate extracts revealed non-significant difference from untreated control. Different studies with other plant extracts these to be. Some studies coincide with present results showing botanicals are safer alternative for beneficial insects as discussed follows: Matter et al. (1993) tested the oils from Aazadirechta indica, Melaia azadirachta Mthusensua, Melia volkinsis Gurla, Citrus aurantium L. and geranium on C. sepumpunctata in the laboratory. None of them affected the survival and behavior of C. septumpunctata and also consumption of the aphids. The ether extract of neem kernel was safer than synthetic insecticide to C. septumpunctata. The order of safety was neem seed kernel extract, endosulfan, quinalphos, malathion and monocrotophos (Guddewar et al., 1994). Also, Sarmah (2009) studied the impact of aqueous plant extracts (APEs) rhizome of Acorus calamus (L), leaves and stem of Xanthium strumarium (L), whole plant of Polygonum hydropiper (L) and Clerodendron infortunatum (Gaertn), on survival and feeding of Stethorus gilvifrons, a potent coccinellid predator of red spider mite. The APEs, even at higher concentration (10\%), caused no mortality to the adults of $S$. gilvifrons for 14 days, and no significant change in feeding after $24 \mathrm{~h}$ was observed, in comparison with untreated control.

Major flavonoids present in Punica granatum (Daru) were tested and found that quercetin was the most effective with respect to causing mortality in aphids. In accordance to these results dietary quercetin $(0,0.005$, $0.05,0.5$ and $1.75 \%$ quercetin by weight) can inhibit postembryonic development and cause histological changes in larvae and females of $D$. melanogaster by blocking steroid hydroxylase activity involved in the moulting process of insect pests (Mitchell et al., 1993). Similarly, quercetin, myricetin, isoquercetin and rutin were found in crude flavonoid extract of $A$. squamosa leaves which at $0.09 \mathrm{mg} / \mathrm{ml}$, caused $100 \%$ mortality of adult Callosobruchus chinenesis (Kotkar et al., 2002). Mesbah et al. (2007) evaluated mode of action of quercetin as a synergist in combination with insecticides. With results they proved the synergistic effect of quercetin when combined with four insecticides, namely, profenofos (organophosphates), deltamethrin (pyrethroid), tebufenozide and hexaflumuron (insect growth regulators) against the cotton leaf worm. Ateyyat et al. (2012) reported that flavanone naringine and the two flavanols, quercetin dehydrate and rutin hydrate, when tested at $100 \mathrm{ppm}, 1000 \mathrm{ppm}$ and 10,000 ppm were successfully proven as aphicides against the woolly apple aphid (WAA) Eriosoma lanigerum (Hausmann). All the three flavonoids at higher concentration led to a significant increase in nymphs mortali- 
ty. Similar results were obtained with the flavonoids tested during present study giving highest mortality of $80 \%$.

Antifeedant effects of naturally occurring quinones and synthetic quinones such as 1,4-naphthoquinone, juglone, 2-methoxy-1,4-naphthoquinone, plumbagin and 2,3dimethoxy-5-mehtyl-1,4-benzoquinone were determined for the third instar cabbage looper larvae (Trichoplusia ni) by a leaf disc choice bioassay. T. ni larvae when fed with leaves treated with juglone and plumbagin, consumed less leaf area and weighed significantly less than control (Akhtar et al., 2012).

The study strongly suggests usage of Punica granatum peel for the control of rose aphids, also gives an insight into its effect on beneficial generalist predators (lady bird beetle), and its compatibility with them. These observations will be helpful in developing an IPM module with the possible use of this plant extract in ornamental greenhouse crops.

\section{Conclusion}

In conclusion, present results indicated that wild pome granate peel and seed extracts showed high toxicity towards aphids which is proven by obtained $\mathrm{LC}_{50}$ values at $48 \mathrm{hr}(35$ and $4 \mathrm{mg} / \mathrm{ml})$ of both peel and seeds extracts respectively. Interestingly, both plant extracts as seed or peel, did not show any toxic effect for lady bird beetle. Field bioassays also proved their affectivity against these pests up to more than a week period under green house conditions. This study for the first time reports the toxic effect of wild pomegranate (daru) fruit peel aqueous extract against rose aphids.

\section{ACKNOWLEDGEMENTS}

Financial support provided by DST, Ministry of Science and Technology, India, is greatly acknowledged. Facilities and workspace were provided by Chairperson and Head, Department of Zoology, Panjab University, Chandigarh, which is gratefully acknowledged.

\section{REFERENCES}

Akhtar, Y., Isman, M.B., Niehaus, L.A., Lee, C.H. and Lee, H.S. (2012) Antifeedant and toxic effects of naturally occurring and synthetic quinones to the cabbage looper, Trichoplusia ni. Crop Protection. 31 (1): 8-14.

Ateyyat, M., Abu-Romman, S., Abu- Darwish, M. and Ghabeish, I. (2012) Impact of flavonoids against woolly apple aphid, Eriosoma lanigerum and its sole parasitoid, Aphelinus mali. Journal of Agricultural Science. 4: 2.

Chebaibi, A. and Filali, F.R. (2013) Bactericidal activity and phytochemical screening of Moroccan pomegranate (Punica granatum L.) peel aqueous extract. Journal of Medicinal Plants Research. 7 (14): 887-891.

Dahham, S.S., Ali, M.N., Tabassum, H. and Khan, M. (2010) Studies on antibacterial and antifungal activity of pomegranate (Punica granatum L.). American-Eurasian journal Agriculture and Environmental Science. 9 (3) : 273281.
Devi, A., Singh, V. and Bhatt, A.B. (2011) In vitro antibacterial activity of Pomegranate and daru (wild pomegranate) against dental plague bacteria. International journal of Pharmacy and Pharmaceutical sciences. 3 (4): 182 184.

Dhembare, A.J., Deokar, M. and Kolte, P. (2011) Efficacy of some plants extracts against rose aphids, Macrosiphum rosaeformis (Davis). Journal of Experimental Zoology India. 14 (1): 325-327.

Dipak, G., Axay, P., Manodeep, C. and Jagdish, K. (2012) Phytochemical and pharmacological profile of Punica granatum. International Research Journal of Pharmacy. 3 (2): 65-68.

Ghaly, N.S., Mina, S.A., Abdel-Aziz, N.F. and Sammour, E.A. (2014) Insecticidal activity of the main flavonoids from the leaves of Kalanchoe beharensis and K. longiflora. Journal of Natural Products. 7: 196-202.

Golawaska, S. and Lukasik, I. (2012) Antifeedent activity of luteolin and genestein against the pea aphid, Acyrthosiphon pisum. Journal of Pest Science. 85 (4): 443-450.

Guddewar, M.B., Shukla, A., Chandra, R., Pandey, S. and Saini, M.L. (1994) Tabenaemontana coranaria B. Apocynacae, a potential source of botanical insecticides.Plant Protection Bulletin, 46:1-5.

Hamouda, A.B, Chaieb, I., Daami-Remadi, M. and Laarif, A. (2015a) In vitro evaluation of insecticidal and antifungal potencies of fruit peel extracts of pomegranate (Punica granatum). Central European journal of experimental biology. 4 (1): 11-15.

Hamouda, A.B., Mechi, A., Zarrad, K., Laarif, A. and Chaieb, I. (2015b) Disruptive effects of pomegranate, Punica granatum Linn. (Lythraceae) extracts on the feeding, digestion and morphology of Spodoptera littoralis (Boisduval) (Lepidoptera: Noctuidae). Entomology and Applied Science Letters. 2 (2): 1-6.

Iqbal, M.F., Kahloon, M.H., Nawaz, M.R. and Javid, M.J. (2011) Effectiveness of some botanical extracts on wheat aphids. The Journal of Animal and Plant Sciences. 21 (1): 114-115.

Jung, J.S. (2015) Insecticidal effects from ethanol extracts of root peel, stem peel, and fruit peel of pomegranate (Punica granatum L.) on house dust mite. International journal of bio-science and bio-technology. 7 (2): 25-36.

Kotkar, E., Mendki, P.S., Sadan, S.V., Jha, S.R. and Maheshwari, V.L. (2002) Antimicrobial and pesticidal activity of partially purified flavonoids of Annona squamosa. Pest Management Science. 58: 33-37.

Kumar, K. and Chapman, R. B. (1984) Toxicity of insecticides to cabbage aphid, Brevicoryne brassicae L. New Zealand Journal of Experimental Agriculture. 12: 5558.

Matter, M.M., Marei, S.S., Moawad, S.M. and Elgengaihi, S. (1993) The relation of Aphis gossypii and its predator Coccinella septumpunctata to some plant extracts. Bulletin of Forestry of Agriculture. 44: 417-432.

Mesbah, H.A., Saad, A.S., Mourad, A.K., Taman, F.A. and Mohamed, I.B. (2007) Joint action of quercetin with four insecticides on the cotton leaf-worm larvae, Spodoptera littoralis Boisd. (Lep. :Noctuidae) in Egypt. Communications in agricultural and applied biological sciences. 72 (3): 445-57.

Mir, M.M., Umar, I., Mir, S.A., Rehman, M.U., Rather, G.H. and Banday, S.A., 2012. Quality evaluation of pome- 
granate crop - a review. International Journal of Agriculture and Biology. 14: 658-667.

Mitchell, M.J., Daniel, P.K., John, R.C. and Stan, L.S. (1993) Effects of plant flavonoids and other allelochemicals on insect cytochrome P-450 dependent steroid hydroxylase activity. Insect Biochemistry and Molecular Biology. 23: 65-71.

Parmar, C. and Kaushal, M.K. (1982) Wild fruits of the subHimalayan region. Kalyani Publishers, Ludhiana. pp 136.

Parmar, C. (2013) Encyclopedia of the edible fruits of the world. Fruitipedia.

Rahimi, H.R., Arastoo, M. and Ostad, S.N. (2012) A comprehensive review of Punica granatum (pomegranate) properties in toxicological, pharmacological, cellular and molecular biology researches. Iranian Journal of pharmaceutical Research. 11 (2): 385-400.

Sarmah, M., Rahmam, A., Phukan, A.K. and Gurusubramanian, G. (2009) Effect of aqueous plant extracts on tea red spider mite, Oligonychus coffeae, Nietner
(Tertranychidae acarina) and Stethorus gilivifrons Mulsant. African Journal of Biotechnology. 8 (3) : 417-423.

Sohail, A., Hamid, F.S., Waheeb, A., Ahmad, N., Aslam, N., Zaman, O., Ahmed, F. and Isman, S. (2012) Efficacy of different botanical materials against aphid, Toxoptera aurantiion on Tea (Camellia sinensis L.) cutting under high shade nursery. Journal of Material and Environmental Science. 3 (6): 1065-1070.

Upasani, S.M., Kotkar, H.M., Mendki, P.S. and Maheshwari, U.L. (2003) Partial characterization and insecticidal properties of Ricinus communis L. foliage flavonoids. Pest management science. 59 (12): 1349-1354.

Xiaofeng, M., Liping, Z. and Bingyong, G. (1999) Studies on the metabolites of actinomyces SIPI-9764. Chinese Journal of Antibiotics. 24: 173-174.

Zhao, X., Yuan, Z., Fang, Y., Yin, Y and Feng, L. (2014) Flavonols and flavones changes in pomegranate (Punica granatum L.) fruit peel during fruit development. Journal of Agricultural Science and Technology.16:16491659. 